\title{
CONTRIBUTION OF GAME TRADITIONAL TO RELATIONSHIP SOCIAL RELATIONS OF CHILDREN SCHOOLS
}

\author{
Th P. Th. Rampisela*, Criezta Korlefura, Jeanete Ophilia Papilaya, and R. F. Tuasikal \\ Counseling Guidance Study Program, \\ Faculty of Education and Teacher Training, Pattimura University \\ *Email: criezta.tapilatu@gmail.com
}

\begin{abstract}
Playing gives children the possibility of active participation and enables development, achieving confidence and better in relations between groups. Through games children can learn social skills and obtain certain rules in games that are temporarily played. Departing this, the purpose of this study was to see how much the contribution of traditional games to the quality of children's social relations at school. This ability is included in the socioemotional aspect. After knowing, the goal in the future also wants to make a model that contains the procedures for applying traditional play methods in the curriculum / school subjects to be able to help children develop optimally the socioemotional aspects. The research method used is the qualitative and quantitative approaches. Quantitative approaches are used primarily about the presentation of children's social behaviors in school; while the qualitative approach is used more intensively in the analysis of the quality of children's social relations, along with the profile and results of the treatment given. The procedures used in this study are research and development procedures. Research and development procedures are used based on the reason that this study is intended to get an initial picture of the quality of children's social relations and it is hoped that in the next research it can produce a product that is the application of traditional games in subjects that aim to improve children's social relations skills. There are some findings obtained first, the results that children who are involved in some traditional games that are performed look more able to do teamwork or good communication with friends. They are indirectly trained in good communication skills and strategies. Secondly, they also after doing a game together, they tend to invite their friends in class to do the same thing. Third, children who are involved in traditional games have a good increase in gross motor activities.
\end{abstract}

Keywords : Game traditional, social relations, children schools.

\section{Introduction}

Play is a unique phenomenon that accompanies our lives, from an early age. There are several games that are shown for various age groups of children and adults. Play is also a cultural heritage that is passed down from generation to generation. However, over time and the times, most children's games have begun to change. Many traditional games have been forgotten and disappeared, because at this time children no longer know the game.

According to Kovacevic and Opic (2014) traditional games have a very large meaning and are able to leave an impression about childhood for everyone who plays it. Strengthening the statement that traditional games have great meaning, the fact that in traditional games many values are contained, including the values of cooperation, sportsmanship, courage, tolerance, self-confidence and so on (Solikhatun, et al, 2018). In Indonesia, the study of traditional games has been carried out by several people and groups. One of them is by Saddhono and Kuniawan (2017) about the 'slipping' game in Banyumas. From the results of the study found that this traditional game is in the midst of the friction of changing times, especially related to 'brenong braids' (kitchen tools) which are the main equipment in this game. In the past, the kitchen equipment used was an ancient braid 
brenong, but now some of the kitchen utensils are already using modern equipment which according to Banyumas people is more practical and easier to find. Another study was also conducted by Basri (2017) in the Muna community. The results showed that students at SMAN 1 Kontunaga generally did not know folklore, failed to memorize Muna songs, and could not play the traditional game 'kalego'. This game is starting to be forgotten by the local community.

Efforts to develop children's social skills can be done within the school, family and community. At school, children are not only directed to develop academic abilities but also to develop social skills. In essence, school education should support child development. One important aspect in children's development is the ability to relate in the social environment. This ability is included in the socioemotional aspect. This aspect is also often known as social competence. Social competence supports communication skills, academic success, and adaptation in schools, and strengthens peer relationships and creates a positive environment in learning (Akman, 2009; Kemp \& Carter, 2005). Individuals who succeed in social competence can succeed in all types of activities that require interaction with others. Developing the ability of children to establish relationships in the social environment is very necessary, because this is one way to optimize various aspects of child development. This social skills must be developed from the beginning, especially in elementary school age children. So that later this social skills can be a basic capital in community life more broadly. With the explanation of the problem and urgency above, the purpose of this study is to find out how much the contribution of traditional games to the quality of children's social relations and the frequency of child outreach at school.

\section{Research Method}

The research methods used the qualitative and quantitative approaches. Quantitative approaches are used primarily about the presentation of children's social behaviors in school. While the qualitative approach is used more intensively in the analysis of the quality of children's social relations, along with the profile and results of the treatment given. The study was conducted at SD Negeri 1 SPG Training.

Initially the researcher collected the initial data, namely by interviewing the principal and the homeroom teacher who aimed to find out a general picture of the social relations issues that occur in elementary school students in Exercise 1 SPG, especially grade 3 students. Then the researchers gave the measuring instrument The School Social Behavior Scales, Second Edition (SBBS-2) as well as a pre-test to 45 students divided into 2 classes. Class A 23 students, class B 22 students. By comparison the number of male students in class A is 10 , female is 13 . Class B has 8 male students and 14 female students.

a. The School Social Behavior Scales, second edition (SBBS-2; Merrel)

The School Social Behavior Scales, second edition (SBBS-2; Merrel, 2002) issued by Assessment-Intervention Resources. This measurement tool also has the same component as the Social Behavior Scale (SBS) which measures social competence and anti-social behavior in individuals aged 5 to 18 years, both within the scope of the home, school, or community.

The SBBS-2 measuring instrument consists of two main scales, scale A is social competence and scale B is anti social behavior. This measuring instrument can be filled by educators both teachers and administrative staff in the school environment. The SBBS-2 is designed to make it easy and quick for teachers and administrative staff in schools to identify children who have risky behavior (for example, children who have deficits in social 
skills and anti-social problems). This instrument can also be used to find out or evaluate interventions carried out if they are appropriate and monitor the progress or progress of children. SBBS-2 Scale A consists of 32 questions and the answer consists of 5 using a Likert scale. Where if the child has a high score on a scale A indicates that the child has a good social adaptation. Scale A - social competence consists of 14 items - Peer Relations, 10 items - Self-Management / Complience, and 8 items - Academic Behavior.

b. Interview

Interviews were conducted using interview guides that had been made based on the categories measured in SBBS-2. Use this interview to get additional data related to the social relations of the guardians.

c. Observation

The observation guide is designed to look at a picture of a child's activity in class during class time, or when the child is free in class. In addition, observations are also made when the child follows an hour break.

\section{Results and Discussion}

a. Results

The results of data collection using SPSS-2 are presented in the form of pretest and post which have been carried out as follows:

Table 1. Overview of Social Behavior of Class 3 Students Pretest

\begin{tabular}{lcc}
\hline Category & Frequency & Presentation \\
\hline Low $(T$-Score $<46)$ & 5 & $11,11 \%$ \\
\hline Moderate $(47 \leq T$-Score $<92)$ & 32 & $71,11 \%$ \\
\hline High $(T$-Score $\geq 138)$ & 8 & $17,78 \%$ \\
\hline Total & 45 & $100 \%$ \\
\hline
\end{tabular}

Based on data processing filling SBBS-2 as well as a pretest, it is carried out on 45 class 3 students. It can be seen that as many as $17.78 \%$ of teachers rate that students have social behavior or social relations that are classified as good or high and another $11.11 \%$ of teachers believe that these categories of students have relatively low social behavior. The average score of the teacher's assessment of social behavior or social relations of class 3 children is $71.11 \%$.

After measuring the pretest to get preliminary data, 5 students were selected who fall into the category of social behavior or social relations that are still low. The students were then given a traditional game play activity for 2 weeks, with 2 weekly meetings. The traditional game given is the game of Asen, Congklak and Benteng. Then after that the social behavior was measured again, especially to the 5 students, then using the same tools and methods as before. 
Table 2 Overview of Social Behavior of Class 3 Students Posttest

\begin{tabular}{lcc}
\hline Category & Frequency & Presentation \\
\hline Low $(T$-Score $<46)$ & 0 & 0 \\
\hline Moderate $(47 \leq T$-Score $<92)$ & 3 & $60 \%$ \\
\hline High $(T$-Score $\geq 138)$ & 2 & $40 \%$ \\
\hline Total & 5 & $100 \%$ \\
\hline
\end{tabular}

Based on SBBS-2 filling data processing as well as a posttest, conducted on grade 3 students as many as 5 people found based on the results of the pretest, it can be seen that as many as $60 \%$ of teachers rate that students have moderate social behavior and $40 \%$ of other teachers believe that students has a relatively high social behavior. It can be clearly seen that there are significant differences in the social relations skills of students who are treated or participate in traditional games.

In addition to using the SBBS-2 questionnaire, interviews with the homeroom teacher and observation in the school environment were also carried out. In the school environment, parents and children are given the opportunity to socialize together with their friends. This makes children have a good relationship with their friends, although there are also some among those children who seem unable to adjust to friends as if they want to be alone and refuse when invited to play with their friends. This behavior is most evident during breaks or during division of work groups. They find it difficult to communicate their ideas and are not confident in what is conveyed to others.

Other behaviors that appear are differences in the ability to control oneself. This can be seen when children are invited to a group to complete the work. The tendency of a child who is difficult to mingle with his friends, has a tendency to behave in anger with the attitude of his friend if not approved. Inversely related to children who are able to socialize, they tend to communicate something they don't like with that person. In academic terms, there are no significant differences because these children have good abilities. This can be seen from the quiz results, exams and assignments given. They are able to do well, it's just that some of them are not able to communicate everything verbally well.

\section{b. Discussion}

Play is a period that is always associated with the stages of child development. Some games can revive a sense of belonging or togetherness in a certain group, arouse emotions, and bring us back in childhood (Kovacevic \& Opic, 2014). As a phenomenon, the game is very close to our daily lives (Fink, 2000). Play is also an activity that is often done by children that will influence the formation of behavior and as a basis needed in children's development. Bermian can also make children think of the causes and consequences of the behaviors that he displays, and characterize human development. This can be seen the same as most grade 3 students of SD N 1 SPG Ambon Training. Most of them fill empty time or hours by playing. Various types of games they do. Some play alone, or in groups. There are also those who play using tools such as through electronic media or other media.

For children, play has a very important benefit, playing not only for fun but also a need that must be met. Through play activities, children can learn about themselves, others and their environment. Children usually experience sensitive periods, where children begin to be sensitive to accept various efforts to develop their full potential. This period is a very 
good time and is suitable to lay the foundation of growth in developing physical motor skills, cognitive, language, social emotional, self-concept, discipline, art, moral, and religious values. Education is not just preparation for children's lives in the future, but education is life itself. A very meaningful expression about the essence of education links. The issue of education is a very crucial and urgent matter to always be discussed. Because only through quality education a civilization of a society and nation will continue to progress (progress).

Today's modern times, in addition to children being required to be able to keep abreast of the times is also expected in the future children will know the types of traditional games in Indonesia. The interaction of children in the game will arouse the ability of children to judge which is good and not good, for example, there are children who play cheats in the game, surely their friends will give moral punishment by not including children who cheat in the game. Traditional games are able to foster the value of sportsmanship, honesty, and mutual cooperation. This was also seen during the implementation of the traditional playing game 'Asen' there was one child who indirectly invited his friend to act out of line. But soon one of the other friends quickly said that don't act like that. With examples like this through traditional games there are several aspects which are the tasks of child development being targeted and accomplished.

In this study, the results showed that children who were involved in some traditional games performed seemed to be better able to do teamwork or good communication with their friends. They are indirectly trained in good communication skills and strategies. For example also in the game 'Congklak' children are trained to be patient and calm, as well as good strategic skills. With some examples of games given to them, children are also taught soft skills and hard skills. This reinforces the statement that traditional games have great significance, the fact that in traditional games many values are contained, including the values of cooperation, sportsmanship, courage, tolerance, self confidence and so on (Solikhatun, et al, 2018).

They also after the game together, they tend to invite their friends in class to do the same thing. They are increasingly aware that traditional games are also fun activities that they can do when they are together with friends during recess or free time. Because some games require several people who are a team, they tend to invite a number of friends who previously they didn't play too often to join in the game.

From this study it was also found that children who were involved in traditional games had a good increase in gross motor activity. During play they can run, jump, or tasks that require coordination of motor functions and the sense of sight. This is also supported by expert opinion about the importance of gross motor development carried out through the game. Theories put forward by Havirgust (1952) who understand development as an interaction of biological, social, and cultural factors. Facto

\section{Conclusion}

From the research carried out to find out how much the contribution of traditional games to the social relations of students of grade 3 SD N 1 SPG Training. There are several findings as follows: Traditional play can affect the development of child development tasks, for example gross motor skills, collaboration skills, communication skills, ability to set strategies, and so on. Traditional games also indirectly provide encouragement for children when following the activities of teaching and learning in class to choose friends who have never previously made contact learning together. Which means that traditional 
games also help the process of social relations that are formed between him and his classmates.

\section{References}

Basri, A. O. L., Aso, L, Momo, H., A, Mudana, Wayan, I, Taena, L, Salniwati, Janu, L., \& Aswati. (2017). The Valuas of Multicultural Education in Munanese Traditional Culture. Asian Culture and History, 9(1), 33-39. https://doi.org/10.5539/ach.v9nlp33

Basri, A. O. L., Mudana, Wayan, I., \& Rahman, A. (2017). The Negative Stigma Against the Bajo Tribe and its Impact on Local Culture: Study of the Bajo Tribe in Bungin Village of South Konawe. Asian Culture and History, 9(2), 90-95. https://doi.org/10.5539/ach.v9n2p90

Basri, A. O. L., Momo, A. H., Marhadi, A., Rahman, A., \& Aswati. (2017). Concept and Leadership Style in the Story of Munanese Folklore: A Study to the Fairy Tale of Kolope Bhala Tumbu (Gadung/Dioscorea Hispida Dennst). Asian Culture \& History, 9(2), 83-89. https://doi.org/10.5539/ach.v9n2p83

Basri, A. O. L., Momo, H. A., \& Rahman, A. (2017). Strategi Pelestarian Budaya Lokal Masyarakat Muna. Laporan Hasil Penelitian. Kendari: LPPM UHO.

Boro, J., Daimary, R., \& Narzaree, B. (2015). Impact of Globalisation to Traditional Games and Recreation of the Bodos. Journal of Humanities and Social Science, 2(3), 8791. https://doi.org/10.9790/0837-20338791.

Kemp, C \& Carter, M. (2005). Identifying skill for promoting successful inclusion in kindergarten. Journal of Intellectual \& Development Disability, 30(1): 31-44

Sibarani, R. (2012). Kearifan Lokal Hakikat Peran dan Metode Tradisi Lisan. Jakarta: Asosiasi Tradisi Lisan.

Sukirman, dkk. (2004). Permainan Tradisional Jawa. Kepel Press: Yogyakarta 